\title{
A ação de consignação em pagamento como veículo de efetividade da boa-fé objetiva
}

\author{
The legal action of consignment in payment as a means of effectiveness of objective good faith \\ La acción de pago en consignación como medio para la efectividad de la buena fe objetiva
}

Recebido: 08/04/2021 | Revisado: 19/04/2021 | Aceito: 21/04/2021 | Publicado: 07/05/2021

\author{
Rosalina Moitta Pinto da Costa \\ ORCID: https://orcid.org/0000-0002-3673-6912 \\ Universidade Federal do Pará, Brasil \\ E-mail: rosalinacosta@ufpa.br \\ Emanoele Pires da Igreja \\ ORCID: https://orcid.org/0000-0003-2105-4027 \\ Universidade Federal do Pará, Brasil \\ E-mail: manuigreja@gmail.com
}

\begin{abstract}
Resumo
A pesquisa tem por objetivo estudar a ação de consignação em pagamento como veículo de efetividade da boa-fé objetiva. Utilizando o método dedutivo com revisão doutrinária como opção metodológica, inicia-se o estudo da boafé como vetor de conduta social e de concretização dos valores normativos do ordenamento, visando demonstrar que os valores éticos impregnam todos os ordenamentos jurídicos contemporâneos, tendo sido dedicados às normas processuais a fim de alcançar a realização da justiça que retrate um processo efetivo. A seguir, analisa-se a ação de consignação em pagamento como meio para a extinção das obrigações, com relevo, entre as hipóteses listadas no artigo 335 do Código Civil, para a causa injustificada do credor em receber o pagamento da obrigação. Após analisarse a mora accipiendi, enquanto fundamento para a propositura da ação de consignação em pagamento e examinar como os deveres anexos da boa-fé podem alterar a relação jurídica e o seu ajuizamento, conclui-se que a ação de consignação em pagamento, ao prever a suppressio e a surrectio como fundamento para a alegação da mora accipiendi, permite a liberação do vínculo obrigacional pelo devedor pela repetição sistemática, constante e continuada de um determinado comportamento, consubstanciando-se em um veículo que dá efetividade à boa-fé objetiva.
\end{abstract}

Palavras-chave: Consignação em pagamento; Deveres anexos da boa-fé objetiva; Cooperação; Lealdade.

\begin{abstract}
The research aims to study the legal action of consignment in payment as a means of effectiveness of objective good faith. Using the deductive method with doctrinal revision as a methodological option, the study of good faith begins as a vector of social conduct and concretization of the normative values of the legal order, aimed to demonstrate that ethical values permeate all contemporary legal systems, having been dedicated to procedural norms with a view to achieving justice that portrays an effective process. Next, the payment consignment lawsuit is analyzed as a means for the extinction of the obligations, with emphasis, among the hypotheses listed in article 335 of the Civil Code, to the creditor's unjustified cause in receiving the payment of the obligation. After analyzing the delay accipiendi, as a basis for filing the payment consignment lawsuit and how the annexed duties in good faith can alter the legal relation and its filing, it is concluded that the payment consignment lawsuit, at the providing for suppressio and surrectio as a basis for the allegation of delay accipiendi, allows the debtor to release the mandatory bond through the systematic recurrence, constant and continuous of a certain behavior, taking the form of a means that gives effect to objective good faith.
\end{abstract}

Keywords: Payment consignment; Annexed duties of bona fide; Cooperation; Loyalty.

\section{Resumen}

La investigación tiene como propósito estudiar la acción de pago en consignación como medio para la efectividad de la buena fe objetiva. Utilizando el método deductivo con la revisión doctrinal como opción metodológica, el estudio de la buena fe empieza como vector de conducta social y concretización de los valores normativos del ordenamiento jurídico, con el objetivo de demostrar que los valores éticos impregnan todos los ordenamientos jurídicos contemporáneos, dedicándose a las normas procesales con miras a lograr una justicia que retrata un proceso efectivo. Después, se analiza la acción de consignación de pago como medio para la extinción de las obligaciones, con énfasis, entre las hipótesis enumeradas en el artículo 335 del Código Civil, a la causa injustificada del acreedor al recibir el pago de la obligación. Luego de analizar la mora accipiendi, como base para la interposición de la acción de consignación en pago y como los deberes anexos de buena fe pueden cambiar la relación jurídica y su presentación, se concluye que la acción de consignación de pago, al disponer la suppressio y surrectio como base para la alegación de 
mora accipiendi, permite al prestatario liberar del vínculo obligacional mediante la repetición sistemática, constante y continua de una determinada conducta, tomando la forma de un medio que da efecto a la buena fe objetiva.

Palabras clave: Consignación en pago; Deberes adjuntos de buena fe objetiva; Cooperación; Lealtad.

\section{Introdução}

A tutela jurisdicional deve ser capaz de alterar a situação fática das pessoas envolvidas no litígio. Não basta que o direito seja reconhecido pelo órgão jurisdicional, é preciso dar concretude, tanto quanto possível, a quem tenha direito de obtêla. A propositura deste estudo foi motivada pela constatação da morosidade da efetivação da tutela jurisdicional e, consequentemente, dos danos causados à sociedade pela frustração da expectativa de satisfação de um direito - já reconhecido judicialmente ou reconhecido por meio de título executivo extrajudicial, o qual o sistema permite o acionamento da via executiva.

A relevância desta análise reside no fato de que, no Brasil, é constitucionalmente garantido ao cidadão o direito à tutela jurisdicional, porém a efetivação da tutela executiva carece de dispositivo expresso. De fato, um dos grandes entraves no direito processual brasileiro é a efetividade da tutela, que abrange a eficácia da prestação jurisdicional. Desse modo, pretendese aqui analisar uma forma de defesa heterotópica admissível no sistema processual brasileiro como meio autônomo de impugnação de execução (Martins, 2005, p. 370): a ação de consignação em pagamento.

O direito disciplina as relações jurídicas que se formam entre os indivíduos, os quais, por viverem em sociedade, dependem uns dos outros para atender às suas necessidades. Destarte, a fim de satisfazê-las, celebram convenções de natureza jurídica diversa, estabelecendo, assim, um vínculo, por meio do qual limitam a sua liberdade, obrigando-se a fornecer uma prestação.

Dessa forma, da celebração de convenções, surge uma complexidade de relações jurídicas obrigacionais vinculativas, que desde o início se encaminham para uma finalidade: a satisfação do interesse da prestação. Nessa perspectiva, nota-se que não são incomuns as situações em que o devedor tem de procurar meios para solver a prestação porque o credor resiste a cumprir a obrigação à qual está vinculado. Tal situação faz-se mais grave quando o suposto devedor corre o risco de ter o seu nome inscrito em diversos cadastros de maus pagadores.

Assim, a consignação é instituto de direito material e de direito processual que satisfaz o interesse do devedor em liberar-se do vínculo obrigacional mediante provimento jurisdicional, nos casos em que a obtenção da quitação é obstada pelo credor. Diante disso, esta pesquisa tem como objetivo compreender se as manifestações da boa-fé objetiva, se configuradas, podem ser albergadas pela ação de consignação em pagamento, enquanto fundamento para o devedor alegar mora accipiendi e, consequentemente, atingir a efetividade da prestação da tutela jurisdicional.

\section{Metodologia}

Primeiramente, é imprescindível a formulação de um método para a pesquisa progredir e edificar-se. Logo, é necessário um "desenho" funcional da forma como foram buscadas as respostas aos objetivos almejados.

Nesse intento, esta pesquisa foi desenvolvida a partir da utilização do método dedutivo com revisão doutrinária como opção metodológica. De acordo com Marconi e Lakatos (2003, p. 92), o método dedutivo “[...] tem o propósito de explicar o conteúdo das premissas [...]", sustentando de modo completo a conclusão. No mesmo sentido, para Gil (2008, p. 9), o método dedutivo "parte de princípios reconhecidos como verdadeiros e indiscutíveis e possibilita chegar a conclusões de maneira puramente formal, isto é, em virtude unicamente de sua lógica". Diante disso, este estudo teórico serve-se de dois meios de análise: a perspectiva histórico-evolutiva e a perspectiva dogmática.

Quanto à leitura histórica, Savigny (1898, pp. 220-224), fundador do historicismo jurídico, afirma que se deve 
observar, a priori, de onde provém a especial expressão do pensamento diante da qual nos encontramos; a posteriori, é preciso que tenhamos suficientemente presente a ideia de todo o complexo das relações históricas e dogmáticas, concernentes ao esclarecimento do ponto particular, descobrindo desde logo as suas correlações. Ademais, Prodanov e Freitas (2013, p. 37) ressaltam que o método histórico permite uma melhor compreensão das instituições e de suas influências na sociedade, a partir de uma investigação de acontecimentos ao longo do tempo.

Assim, essa foi a metodologia utilizada para fins de compreensão do desenvolvimento da ação de consignação em pagamento no sistema processual brasileiro e do papel da boa-fé no direito das diversas nações no curso do tempo. Fez-se necessário entender que a boa-fé não desempenhou, segundo Taborda (2001), um papel linear, mas assumiu um perfil dogmático diverso, cuja origem remonta ao direito romano. Nesse mesmo sentido, a partir de tal método, examinou-se a evolução do pagamento em consignação, desde a perspectiva romana do abandono da coisa devida, caso restasse evidente o desinteresse do credor, até o surgimento da ação de consignação enquanto instrumento processual adequado para a liberação do devedor do vínculo obrigacional.

De outra banda, no que tange à perspectiva dogmática, optou-se pela pesquisa exploratória normativa atrelada ao diálogo com as produções bibliográficas, no intuito de verificar o modo como o ordenamento jurídico brasileiro recepciona os institutos da boa-fé objetivada. Em paralelo, a fim de observar se os deveres anexos da boa-fé podem ser albergados pela ação de consignação em pagamento, recorreu-se a Venosa (2005) e a Gagliano e Pamplona Filho (2018) para a análise do conceito de mora accipiendi, bem como a Tartuce (2017) e a Patti (1999) para a compreensão dos deveres anexos da boa-fé e de suas consequências na modificação da relação jurídica, o que possibilita, inclusive, a configuração de hipótese de cabimento para a propositura de ação de consignação em pagamento.

\section{Resultados e Discussão}

\subsection{A boa-fé como vetor de conduta social e de concretização dos valores normativos do ordenamento}

A priori, é importante constatar que a boa-fé, ao longo dos séculos, não desempenhou um papel linear. De fato, ao examinar o direito das diversas nações no curso do tempo, notam-se perfis dogmáticos e de relevância sistemática diversa. A noção de boa-fé provém do direito romano. Seu significado vem da palavra fides, que remete à ideia de "confiança" ou de "fé" (Taborda, 2001, p. 24). A expressão polissêmica fides era entendida amplamente na Antiguidade não só como fundamento da justiça, mas também como "lealdade e respeito à palavra dada" (Martins-Costa, 2018, p. 52), sendo entendida no direito romano como uma promessa de cumprimento da obrigação, que encerrava a ideia de ordem moral.

O conceito de boa-fé, no sentido lato do termo, é expresso de forma objetiva por Romain (2000), para quem o princípio da boa-fé estava ligado ao padrão de comportamento do bonus vir: "O contrato é, no direito romano, o campo privilegiado em que se exprimiu o princípio da boa-fé, ligado ao padrão de comportamento do bonus vir. A filosofia do ato contratual está profundamente imbuída dele" (Romain, 2000, p. 34). De fato, a fides não passava de mera força vinculativa para as partes, as quais ficavam obrigadas a cumprir a sua palavra, independentemente da forma em que foi dada. Inclusive, para Cícero o fundamento da justiça era a boa-fé, ou seja, a fidelidade exata à palavra dada e aos compromissos.

A boa-fé começou a ser considerada princípio geral com o surgimento da compilação justinianeia (Morais, 2019) em que se visava "a vedação aos negócios cujo escopo neles externado se revelasse ilícito ou contrário aos bons costumes" (Zanetti, 2008, p. 27). No século XIX, com a Escola Positivista, os princípios do direito eram aplicados tendo em vista a manutenção da liberdade individual e da propriedade privada (Zanetti, 2008, p. 27). No contexto do Estado Liberal, o princípio da boa-fé estava intimamente associado ao princípio do pacta sunt servanda, em que se buscava o exato cumprimento contratual, afastando-se, inclusive, a possibilidade de revisão do contrato, pois os contratos deveriam ser cumpridos conforme foram firmados. Segundo Romain (2000, p. 962), o papel reservado à boa-fé era de mero reforço do vínculo contratual. 
O princípio da boa-fé apresenta-se sob duas modalidades: subjetiva e objetiva. O Código Civil (CC) alemão de 1900 permitiu a diferenciação entre a boa-fé objetiva e a subjetiva com as chamadas cláusulas gerais, passando a admitir a objetiva como fonte autônoma de direitos e de obrigações (Silva, 2006, p. 32). Ao longo da década de 80 do século XX, reconheceu-se o papel da boa-fé sob a égide da noção de solidariedade social (Falco, 2010, p. 6 et seq.), delineando-se uma nova faceta atrelada à conduta dos negociantes - a denominada boa-fé objetiva. Desse modo, saltou-se da subjetivação para a objetivação.

No âmbito nacional, a Constituição Federal de 1988 (Brasil, 1988) erigiu, no seu artigo 3. ${ }^{\circ}$, inciso I, como um dos objetivos da República a construção de uma sociedade solidária (Mello, 2017, p. 77). Assim, haveria um dever fundamental de solidariedade, do qual decorreria o dever de não quebrar a confiança e de não agir com deslealdade. Portanto, faz-se necessário um comportamento probo do indivíduo. Para que tal diretriz seja alcançada, a exigência da eticidade deve nortear as condutas de todos os indivíduos, inclusive daqueles envolvidos em relações obrigacionais.

Nesse contexto, a boa-fé apresenta-se como vetor das condutas de todos os que participam da relação jurídica processual, como função regulamentar das garantias constitucionais processuais.

Com a modificação das relações obrigacionais entre os sujeitos envolvidos, fez-se necessário reformular o ordenamento jurídico. Assim, o Código Civil em vigor adotou o princípio da eticidade, valorizando as condutas guiadas pela boa-fé, especialmente no âmbito obrigacional. A boa-fé objetiva, por dizer respeito à conduta obrigacional típica, é a dimensão externa da boa-fé em geral.

Ao estipular um padrão de lealdade e de probidade nas relações privadas, ao veicular o imperativo da tutela da confiança e do atuar probo e honesto, a boa-fé assume diversas faces, que delineiam modelos jurídicos de comportamento e de atuação, os quais têm a aptidão de fazer novas as vetustas disposições legislativas, em um trabalho engenhoso de adequação das emergentes situações jurídicas ao ordenamento. Assim sendo, a boa-fé objetiva cria situações jurídicas que modulam os vínculos e causam obrigações, sem mesmo instituir laços subjetivos ou pessoais.

A boa-fé objetiva é comumente tratada no Direito Civil como princípio norteador das relações contratuais, mas, no que tange ao sistema processual, orienta a conduta das pessoas que, de qualquer forma, participam do processo (Donizetti, 2017, p. 79), devendo, desse modo, ser compreendida como uma norma de conduta (Didier Jr., Braga, \& Oliveira, 2020, p. 133). Por essa razão, o artigo 5..$^{\circ}$ do Código de Processo Civil (CPC) de 2015 enuncia que "aquele que de qualquer forma participa do processo deve comportar-se de acordo com a boa-fé". Trata-se evidentemente, de uma exigência de boa-fé objetiva, isto é, de um padrão esperado de comportamento diante dos valores de uma comunidade.

Para Reale (2010, p. 657), a boa-fé objetiva compreende a fixação de um modelo de conduta leal, denominado pelo doutrinador "honestidade pública", estando, portanto, intimamente ligada aos princípios da lealdade processual e da cooperação (Bueno, 2016, p. 98). A boa-fé é um dever de conduta - para as partes, bem como para o magistrado - baseado na expectativa razoável em determinada circunstância.

Nessa perspectiva, por força desse princípio, são vedados comportamentos desleais ou contraditórios, o que sugere uma clara aproximação entre o direito e os valores éticos e morais mencionados no artigo $3 .^{\circ}$, inciso I, da Carta Magna, que visa, como objetivo da República, a construção de uma sociedade solidária. Destarte, ficam vedadas todas as iniciativas que podem frustrar a justa expectativa gerada nas partes da relação processual, exigindo delas uma conduta positiva e, igualmente, a omissão maliciosa.

Do princípio da boa-fé, emanam deveres jurídicos gerais, denominados "deveres gerais de conduta”, porque são aplicáveis a todos os sujeitos que estejam em posição jurídica similar. Segundo Scarpinella Bueno (2016, p. 98), que se apoia em Baumgärtel (1973, p. 86), a doutrina alemã observa quatro casos de aplicação da boa-fé objetiva ao processo, situações que vedam o comportamento contraditório: a prática de ato (posterior) apto a frustrar a legítima preservação da coerência de outro ato (anterior) por determinado sujeito (venire contra factum proprium) e suas variantes, como a suppressio (tornar impossível a 
prática de um ato porque a omissão em praticá-lo é capaz de gerar confiança legítima em outro sujeito), a surrectio (é a outra face da suppressio, pois consiste no nascimento de um direito, sendo nova fonte de direito subjetivo, consequente à continuada prática de certos atos) e o tu quoque (prática de ato que, ao romper a legítima confiança entre os sujeitos, introduz novo elemento prejudicial na relação jurídica).

No que tange a esses casos, para o presente artigo, importa examinar a suppressio e a surrectio enquanto deveres processuais que garantem o atingimento do dever fundamental de solidariedade, vedando, no campo do direito processual, quaisquer abusos processuais. Nesse sentido, não há dúvida quanto à importância da compreensão da boa-fé objetiva na busca de um processo civil mais ético.

\subsection{Suppressio e surrectio como manifestações da boa-fé objetiva processual}

A sociedade contemporânea tem assistido a uma contínua reformulação no âmbito processual fundamentada na busca da efetividade da prestação da tutela jurisdicional, tendo a boa-fé assumido, nos últimos tempos, papel especial em todos os momentos da relação negocial. A recuperação dos fundamentos éticos deu-se em todo o direito contemporâneo, inclusive no âmbito processual. Portanto, os valores éticos permeiam todos os ordenamentos jurídicos contemporâneos, e especial atenção tem sido dedicada às normas processuais tendo em vista a realização da justiça que retrate um processo efetivo.

De acordo com Grinover (2002), mais do que nunca, o processo deve ser informado por princípios éticos. A relação jurídica processual, estabelecida entre as partes e o juiz, rege-se por normas jurídicas e por normas de conduta. De há muito, o processo deixou de ser visto como instrumento meramente técnico, para assumir a dimensão de instrumento ético dedicado a pacificar com justiça.

A boa-fé objetiva pode ser compreendida como um dever geral de honestidade processual. Assim, já se consignou alhures que se impõem deveres anexos, justamente a fim de resguardar o fiel processamento da relação obrigacional. Dentre as manifestações da boa-fé, destacam-se dois deveres anexos: suppressio e surrectio. Inicialmente, é mister ressaltar que o objetivo desta subseção é compreender de que forma uma contradição no comportamento do titular da posição jurídica, ao longo de um determinado tempo, pode modificar a própria relação jurídica.

O dever anexo de suppressio tem sido definido como "a situação do direito que, não tendo sido, em certas circunstâncias, exercido durante um determinado lapso de tempo, não possa mais sê-lo por, de outra forma, se contrariar a boafé" (Cordeiro, 2007, p. 797). No mesmo sentido, Tartuce (2017, p. 141) afirma que a suppressio é expressão proposta para traduzir o termo alemão Verwirkung, que significa "a supressão, por renúncia tácita, de um direito ou de uma posição jurídica, pelo seu não exercício com o passar dos tempos". Pode-se notar o sentido de tal instituto mediante a leitura do artigo 330 do $\mathrm{CC} / 2002$, o qual prevê que "o pagamento reiteradamente feito em outro local faz presumir renúncia do credor relativamente ao previsto no contrato".

Nessa perspectiva, a aplicação da suppressio traduz-se na situação em que incorre uma pessoa que, tendo suscitado noutra situação, por força de um não exercício prolongado, a confiança de que a posição em causa não seria atuada, não pode mais fazê-lo por imposição da boa-fé. No direito processual, a aceitação da boa-fé é pacífica, mas sua aplicação é limitada em razão das rígidas disposições sobre os prazos processuais, visto que o exercício extemporâneo de um direito é alcançado pela preclusão diante da dinamicidade do caminhar do processo.

É importante notar que, pelas definições da suppressio trazidas à baila, para que tal instituto esteja configurado, faz-se necessário, a priori, que exista contradição no comportamento do titular da posição jurídica e, a posteriori, que essa contradição persista durante um lapso temporal. Na suppressio, segundo Patti (1999), o lapso temporal é o período de desenvolvimento da confiança em decorrência da inércia do titular.

Acerca do pressuposto da confiança, mencionado por Patti, Júlio Neves (2016, p. 96) afirma que a confiança investida 
é um pressuposto cumulativo para a aplicação da boa-fé, o qual decorre do próprio lapso de tempo, na medida em que, quanto maior o tempo que o indivíduo se mantém inerte em relação ao exercício de seu direito, tanto maior será a confiança gerada na contraparte de que não será invocado. Logo, é possível observar que a realidade social da suppressio, que o direito procura orientar, está na ruptura das expectativas de continuidade da autoapresentação praticada pela pessoa que, tendo criado, no espaço jurídico, uma imagem de não exercício, rompe, de súbito, o estado gerado.

Outro instituto que merece destaque é a surrectio (Erwirkung), a qual, de acordo com Tartuce (2017, p. 142), caracteriza-se pelo surgimento de um direito, de forma complementar ao direito legislado, contrato ou judicial, não existente antes. Cordeiro (2007, p. 821) esclarece que surrectio e suppressio são duas faces da mesma moeda, visto que a suppressio seria, na verdade, uma forma da surrectio, observada sob o ponto de vista do titular do direito, a cuja atuação a contraparte pode furtar-se.

Para ocorrer a surrectio, deve haver a repetição sistemática, constante e continuada de um determinado comportamento, o que cria um direito novo. Esse direito consubstancia-se na expectativa, a ser mantida pelo menos como probabilidade, de regularidade e de continuidade da situação fática subjacente, ou, por outro lado, da ausência de qualquer outra solução diferente. A surrectio expressa, portanto, a circunstância do surgimento de um direito não existente antes, o qual, na efetividade social, já vinha sendo considerado como presente (Mello, 2017, p. 85).

Desse modo, define-se a surrectio pela exigência de um lapso temporal durante o qual se atua uma situação jurídica em tudo semelhante ao direito subjetivo que vai surgir, requerendo-se uma conjunção objetiva de fatores que culminam na constituição de um novo direito. Diante disso, José Fernando Simão afirma que, enquanto a suppressio constitui a perda de um direito ou de uma posição jurídica pelo seu não exercício no tempo, a surrectio é o surgimento de um direito diante de práticas, de usos e de costumes reiterados, visando garantir que seja mantido o ajuste tacitamente convencionado. Isso porque a pretensão de exigir uma situação jurídica a qual foi ou não exigida durante um lapso temporal frustraria uma expectativa legítima construída e mantida ao longo de toda a relação processual (Simão, 2008, p. 38 como citado em Tartuce, 2017, p. 142). Decerto, o que esses dois institutos visam não é a punição do titular de um direito não exercido, mas a proteção da parte contrária.

Do exposto, depreende-se que, para que a suppressio seja configurada, faz-se mister a presença de três elementos: a omissão no exercício de um direito, o transcurso de um período e a objetiva deslealdade e intolerabilidade do exercício posterior do direito. Em contraponto, a surrectio surge do exercício continuado de uma ação não prevista em contrato, implicando nova fonte de direito subjetivo, criando para o outro sujeito da relação um direito perdido pelo credor (Mello, 2017, p. 86).

Com base na conceituação desses dois deveres anexos da boa-fé objetiva, visa-se compreender de que forma tais institutos podem modificar tacitamente a relação jurídica em uma obrigação cujos credores encontram-se em mora, a partir da análise de duas situações jurídicas. Primeiro, constitui a surrectio ou a suppressio fundamento para o devedor alegar mora accipiendi, em caso de pagamento reiteradamente feito em local diverso do consignado em contrato? Ou, ainda, de que modo esses dois institutos podem vir a alterar o lugar de propositura da ação?

\subsection{A ação de consignação em pagamento como veículo de efetividade da boa-fé objetiva}

\subsubsection{A ação de consignação em pagamento como instrumento processual adequado para o devedor se liberar do vínculo obrigacional}

Inicialmente, é oportuno destacar que, diferentemente do que ocorre hodiernamente, no direito romano o devedor ficava autorizado a abandonar a coisa devida, ou seja, o objeto da prestação, sempre que ficasse evidente o desinteresse do credor em recebê-lo (Salvatore, 1950, p. 220). Isso significa que, se notória a recusa do credor em receber a prestação, o 
devedor poderia fazer uma oferta real; persistindo a recusa, o devedor liberava-se da obrigação. Posteriormente, no período justiniano, a consignação surge com caráter liberatório do vínculo obrigacional, a partir do depósito da quantia certa ou da coisa devida.

A "ação de consignação em pagamento é o instrumento processual adequado para que o devedor, nos casos previstos na legislação, efetue o depósito da prestação devida" (Gajardoni, Dellore, Roque, \& Oliveira Jr., 2018, p. 877). Nesse diapasão, na esteira da melhor doutrina, o pagamento em consignação é também definido como "o meio indireto de o devedor, em caso de mora do credor, exonerar-se do liame obrigacional, consistente no depósito judicial (consignação judicial) ou em estabelecimento bancário (consignação extrajudicial), da coisa devida, nos casos e formas da lei” (Diniz, 2007, p. 313).

A ação de consignação em pagamento é, portanto, meio indireto de pagamento que visa resolver a obrigação assumida (Diniz, 2007, p. 244). Logo, almeja-se com o ajuizamento dessa ação a finalização do vínculo jurídico entre devedor e credor decorrente de obrigação assumida anteriormente, tal como prevê o artigo 540 do CPC, isentando o devedor dos riscos e de eventual obrigação de pagar juros moratórios, já que a consignação afasta a aplicação das regras do inadimplemento.

Cambi et al. (2017) afirmam que "seria insuficiente somente reconhecer a mora do credor e não estabelecer mecanismos que permitam ao devedor, ainda que indiretamente, a realização do pagamento e o alcance da consequente liberação". Nesse mesmo sentido, os autores ainda dispõem que duas medidas foram tomadas para combater a vulneração da boa-fé bem como para prestigiar o reconhecimento e a proteção do direito à liberação: a concepção do mecanismo da consignação e a previsão de hipóteses em que, por algum fato ou ato relacionado ao credor, o devedor tem a consignação ao seu alcance.

Assim, a ação de consignação em pagamento tem por finalidade ser o instrumento processual adequado para que o devedor efetue o depósito da prestação devida, a fim de se liberar do vínculo obrigacional e, consequentemente, afastar a mora bem como suas consequências. Humberto Theodoro Júnior (2016, p. 49-51) salienta que a ação de consignação em pagamento é predominantemente declarativa, visto que a sentença limita-se a reconhecer a eficácia liberatória do depósito promovido pelo devedor.

Desse modo, em conformidade com Antonio Marcato (1996, p. 16), o pagamento em consignação destina-se à solução de obrigações que têm por objeto prestações já vencidas e ainda pendentes de satisfação, pouco importando se essa pendência decorre de causa atribuível ao credor ou resulta de outra circunstância obstativa do pagamento por parte do devedor, valendo-se este último de tal instrumento a fim de liberar-se do vínculo que o submete ao accipiens. No âmbito do processo executório, Faro (2012, p. 5) dispõe que a ação de consignação em pagamento tem por finalidade evitar a incidência de astreinte, isto é, o devedor pode fazer uso da sua faculdade de consignar o pagamento da quantia a que foi condenado a pagar enquanto a discute em juízo.

Diante disso, o artigo 539 do CPC dispõe que "nos casos previstos em lei, poderá o devedor ou terceiro requerer, com efeito de pagamento, a consignação da quantia ou coisa devida". Logo, percebe-se que o permissivo legal refere-se aos embaraços sofridos pelo devedor que busca liberar-se da obrigação, mas não consegue lograr êxito. Nessa perspectiva, segundo Theodoro Júnior (2016, p. 50), a ação consignatória permite que, diante de prestações passíveis de consignação, o devedor consiga efetuar o pagamento com a segurança jurídica de plena eficácia.

Tartuce (2017, p. 201) afirma que a letra da lei autoriza ter como objeto da consignação bens móveis e imóveis, desde que o objeto da ação esteja relacionado a uma obrigação de dar. De igual modo, Gonçalves dispõe que: "O fato de a consignação realizar-se por meio de um depósito limita a sua aplicação às obrigações de dar, podendo tomar a forma de entrega ou restituição" (Gonçalves, 2015, p. 292). Assim sendo, observa-se que somente as obrigações de dar podem ser objeto de consignação, não sendo admitida consignação em pagamento de obrigações de fazer e não fazer. A razão de tal impedimento é a própria impossibilidade material, pois, no caso de o credor recusar-se a receber prestação de fazer ou de não 
fazer, deve-se converter a obrigação em perdas e danos.

Ademais, em relação às obrigações de entrega da coisa, Gajardoni, Dellore, Roque e Oliveira Jr. (2018, p. 891) ressaltam que é possível a consignação após o prazo do cumprimento da obrigação. Entretanto, o pedido poderá não ser acolhido se o credor comprovar que a prestação tornou-se inútil em decorrência do decurso do tempo.

O Código Civil apresenta um rol não taxativo das hipóteses que autorizam a consignação, isto é, as circunstâncias que autorizam o ajuizamento da ação de consignação. $\mathrm{O}$ artigo 335 prevê os fatos que autorizam o ajuizamento da ação de consignação em pagamento e possuem por fundamento 1) a mora do credor (incisos I e II) (a qual será analisada em tópico específico) e 2) circunstâncias inerentes à pessoa do credor que impedem o devedor de cumprir a obrigação acordada (incisos III a V).

Para Gagliano e Pamplona Filho (2018, p. 238), as outras hipóteses que ensejam a propositura da ação de consignação em pagamento dizem respeito aos casos em que o credor é incapaz e, em razão da sua condição, não poderá receber o pagamento ou, ainda, quando o credor está ausente ou a residência do credor é em lugar incerto ou de difícil acesso (art. 335, III, do CC). Os doutrinadores também apresentam as hipóteses em relação, a priori, à dúvida quanto a quem seja o credor legítimo e, a posteriori, quando ao fato de pender litígio sobre o objeto do pagamento (art. 335, V, CC).

De igual modo, para Tartuce (2017, p. 430), havendo dúvida em relação à titularidade do crédito, poderá o devedor valer-se da consignação para não correr o risco de pagar mal, requerendo a citação dos interessados em receber o pagamento. Já no caso de existir disputa em juízo quanto ao objeto do pagamento entre o credor e o terceiro, deve o devedor livrar-se da obrigação mediante pagamento por consignação a ser realizado pela via judicial.

Em suma, a ação de consignação em pagamento é o instrumento processual adequado para que o devedor possa exonerar-se do liame obrigacional, permitindo a finalização de um vínculo jurídico - entre devedor e credor - decorrente de obrigação assumida anteriormente.

\subsubsection{Mora accipiendi como fundamento para a propositura da ação de consignação em pagamento}

A tendência ao cumprimento de todo vínculo obrigacional retrata uma das aplicações mais explícitas do princípio da confiança: ninguém celebraria negócios jurídicos, contraindo direitos e obrigações, caso não almejasse o cumprimento das prestações que lhe aproveitam. Em contrapartida, as partes têm a consciência da necessidade de cumprir com as incumbências de suas responsabilidades, sob pena de não obterem as prestações a que possuem direito.

O pagamento é, portanto, a realização voluntária da prestação devida e a satisfação do interesse do credor. Coelho (2020) afirma que o credor espera que a obrigação seja cumprida espontaneamente no vencimento, ou seja, que a prestação seja entregue pelo devedor no tempo e no lugar devidos. Tal constatação imprime relevo ao inadimplemento obrigacional, o qual pode ser inadimplemento absoluto ou relativo.

Segundo o entendimento de Venosa (2005, pp. 337-338), o critério da utilidade é o instrumento para diferenciar as duas espécies de inadimplemento. Assim, haverá inadimplemento absoluto quando a obrigação é imprestável ao credor, ainda que o seu cumprimento seja fenomenologicamente possível. Já o inadimplemento relativo está intimamente atrelado à possibilidade de realização da obrigação, que, apesar de não cumprida no tempo do vencimento, é útil ao credor. Destarte, tal atraso é denominado, de acordo com Gagliano e Pamplona Filho (2018, p. 400), de mora do devedor, debendi, solvendi ou debitoris, se o fato for imputável ao devedor, ou mora do credor, credendi, creditoris ou accipiendi, caso o fato seja imputável ao credor.

Portanto, o inadimplemento relativo ocorre quando a prestação não foi cumprida no tempo, no lugar e na forma convencionados. Esse retardamento, segundo tais doutrinadores, caracteriza a mora, que poderá ser tanto do credor (mora accipiendi) quanto do devedor (mora solvendi). 
No mesmo sentido, o doutrinador Caio Pereira (2017, p. 291) observa que a mora é o retardamento injustificado da parte de algum dos sujeitos da relação obrigacional no tocante à prestação, no qual "pode incorrer tanto o sujeito passivo quanto o sujeito ativo da obrigação". Entretanto, o mesmo doutrinador lembra que não é, também, todo o retardamento no solver ou no receber que induz a mora. Algo mais é exigido na sua caracterização. Na mora solvendi, como na accipiendi, há de estar presente um fato humano, intencional ou não intencional, gerador da demora na execução. Isso exclui do conceito de mora o fato inimputável, o fato das coisas, o acontecimento atuante no sentido de obstar a prestação, o caso fortuito e a força maior, impedientes do cumprimento.

Nessa perspectiva, quando existe, pelas circunstâncias da hipótese, uma obrigação para o credor quanto ao recebimento opportuno tempore, está esse em mora quando atrasa o recebimento devido. Nos demais casos, ainda que falte ao credor a obrigação de receber, incumbe-lhe, no entanto, um dever negativo de não se opor a que o devedor se desvencilhe da obrigação (Nery \& Nery Jr., 2014, p. 7). Assim, manifesta-se a mora accipiendi pela recusa injustificada do sujeito ativo em receber a prestação no vencimento. Dessa forma, Gama (2008, p. 356) enumera os requisitos para a configuração da mora accipiendi: (a) oferecimento da prestação pelo devedor, desde que seja completa, no lugar e no tempo oportunos; (b) recusa injustificada (sem justa causa) do credor em receber a prestação, ou de prestar a cooperação necessária decorrente do princípio da boa-fé objetiva de modo a permitir o correto cumprimento da obrigação.

O ordenamento jurídico estabelece que a extinção de uma obrigação dá-se, normalmente, pelo pagamento espontâneo pelo devedor dentro do prazo estipulado, de forma que qualquer interessado na sua extinção pode solvê-la, utilizando, dependendo do comportamento do credor ou das circunstâncias, de meios conducentes à exoneração do devedor. Logo, a oposição à solutio pelo credor compara-se ao retardamento do devedor, e a mora de um equipara-se à do outro. Desse modo, em caso de mora accipiendi ou quando for impossível o pagamento por fatores não imputáveis ao devedor (art. 335 do CC), este último poderá exonerar-se da obrigação por meio da consignação em pagamento, visto que a "ele também interessa o cumprimento da obrigação para liberar-se do vínculo a que está adstrito" (Silva, 1977, p. 19).

Além do credor, o devedor também possui interesse no cumprimento da obrigação assumida para liberar-se do vínculo obrigacional, não sendo, portanto, obrigado a ficar indefinidamente preso a uma determinada relação de obrigação, de tal modo que o credor não pode, sem justo motivo, suprimir ou coarctar o exercício desse direito (Arenal, 2015, p. 36). Diante disso, nota-se que é direito do devedor cumprir a prestação e, consequentemente, obter do credor a quitação da dívida. Para Theodoro Júnior (2016, p. 1408), o depósito em consignação é modo de extinção da obrigação, com força de pagamento, e a correspondente ação consignatória tem por finalidade ver atendido o direito - material - do devedor de liberar-se da obrigação e de obter quitação.

O pagamento em consignação é o meio indireto facultado ao devedor de exonerar-se de uma obrigação que não pode adimplir por culpa do credor (Diniz, 2007, p. 244), o qual consiste no depósito em juízo ou em estabelecimento bancário, nos casos e formas legais. Segundo Cambi et al. (2017, p. 1201), quando se analisam as posições jurídico-subjetivas decorrentes do pagamento como forma de adimplemento, de um lado, verifica-se o direito do credor ao recebimento da prestação e a correspondente obrigação do devedor de realizá-la e, de outro, constata-se o direito do devedor à obtenção de sua liberação e, consequentemente, a obrigação do credor de receber o pagamento. É claro que, a fim de que a consignação tenha força de pagamento, o devedor deve observar os termos da obrigação na forma em que foi pactuada, ou seja, o objeto, o modo e o tempo da obrigação ou, na diç̧ão do artigo 336 do CC, "será mister que concorram, em relação às pessoas, ao objeto, modo e tempo, todos os requisitos sem os quais não é válido o pagamento".

A verificação da existência de mora, em conformidade com o artigo 335, incisos I e II, do CC, é, desse modo, não só um fundamento para a propositura da ação de consignação como também um modo especial de liberar-se da obrigação concedido por lei ao devedor que tem o cumprimento obstado pelo accipiens. Segundo Gonçalves (2015, p. 294), o artigo 335, 
I, do CC trata da recusa injustificada do credor em receber o pagamento ou dar quitação à impossibilidade subjetiva de receber. Tal caso contempla a hipótese de dívida portable, em que o pagamento deve ser efetuado no domicílio do credor, incumbindo a este o ônus de provar a existência de justa recusa (Gama, 2008, p. 240-241). Já o artigo 335, II, do CC prevê a hipótese de inércia do credor no caso de dívida, cujo pagamento é em lugar diverso do domicílio do credor, cabendo a este último a iniciativa de procurar o devedor para o cumprimento da prestação. Dessa forma, permanecendo o credor inerte, ou seja, não fazendo no tempo e no local estabelecido, faculta-se ao devedor consignar judicialmente a coisa devida ou extrajudicialmente a importância em dinheiro.

Sendo assim, ocorrendo a recusa injustificada, o devedor ou o terceiro interessado poderão propor a ação de consignação (Gonçalves, 2019, p. 18), já que estaria configurada uma de suas hipóteses de cabimento (art. 335, I e II, do CC e art. 539 do CPC). É importante observar que a propositura da ação consignatória é um instrumento processual adequado para que o devedor efetue o depósito da prestação devida (Gajardoni, Dellore, Roque, \& Oliveira Jr., 2018, p. 877), independentemente da modalidade da obrigação a que está vinculado, isso por que a obrigação revela-se como uma relação complexa, formada por um conjunto de atos relacionados entre si, que desde o início se encaminha para uma finalidade: a satisfação do interesse da prestação (Tartuce, 2017, p. 354).

Considerando que a prestação é o objeto da relação obrigacional, entende-se que o devedor fica adstrito ao cumprimento da obrigação, podendo o credor exigir o adimplemento da prestação convencionada, a fim de satisfazer o seu interesse (Mello, 2017, p. 67). Essa noção de obrigação atrelada ao vínculo jurídico representa uma tradição bimilenar contida nas Institutas de Justiniano (Noronha, 2013, p. 30) em que se dizia: "a obrigação é o vínculo jurídico pelo qual ficamos adstritos à necessidade de solver uma coisa, em conformidade com as normas jurídicas da nossa cidade".

Diante disso, é oportuno salientar que o pagamento em consignação tem lugar, basicamente, quando há mora na aceitação (mora accipiendi), objeto do presente estudo, ou nos casos de dúvidas no plano material sobre quem deve receber o pagamento, conforme o artigo 335, incisos IV e V, do CC. Na hipótese da mora accipiendi, o credor deve agir de maneira leal e proba para com o devedor, de modo a não recusar ou obstar o adimplemento imotivadamente em decorrência do que Lobo (2005, p. 102) denomina "dever de cooperação".

Em alguns casos, o dever de cooperação é obstado pela multiplicidade de sujeitos envolvidos na obrigação. Isto é, nota-se uma particularidade nas obrigações solidárias ativas pela própria natureza da obrigação, uma vez que o cumprimento da obrigação poderia ser obstado pelo cocredor que não foi acionado pelo devedor para o seu cumprimento, ensejando a possibilidade de também configurar a mora accipiendi. No geral, as obrigações solidárias caracterizam-se pela "multiplicidade de credores e/ou devedores, tendo cada credor direito à totalidade da prestação, como se fosse único, ou estando cada devedor obrigado pela dívida toda, como se fosse o único devedor" (Gonçalves, 2015, p. 130). Hontebeyrie (2004, p. 439) corrobora a caracterização feita por Gonçalves ao afirmar que "a obrigação solidária é uma espécie de obrigação conjunta cuja unidade de prestação se justifica pela unidade de causa geradora".

Sendo assim, observa-se que um grande entrave surge quando há uma obrigação solidária ativa de trato sucessivo, em que um dos credores aciona o devedor para o cumprimento da obrigação, que é cumprida em lugar diverso do pactuado e sem a anuência dos demais cocredores. $\mathrm{O}$ entrave decorre da multiplicidade do vínculo jurídico entre o credor principal, o devedor e os demais credores.

Para Pereira (2017), a solidariedade tem uma só natureza: uma obrigação com unidade objetiva, motivo pelo qual não pode haver a solução sem integridade da prestação. Dessa forma, uma vez iniciada a demanda, opera-se o que Gonçalves e Pereira denominam, respectivamente, "fenômeno da prevenção" (Gonçalves, 2015, p. 143) e "prevenção judicial" (Pereira, 2017, p. 101).

De acordo com o fenômeno da prevenção, bastante parecido com o princípio da prevenção que vige no direito 
processual (arts.106 e 107 do CPC de 1973 e arts. 58 e 60 do CPC de 2015), o devedor só se libera da obrigação pagando ao próprio credor que tomou a iniciativa. No âmbito do direito processual, o fenômeno da prevenção é desenvolvido como um princípio que fixa a competência em função de determinado elemento temporal (Marinoni, Arenhart, \& Mitidiero, 2016, p. 67). Todavia, no âmbito do direito material, o Código Civil, em seu artigo 268, prevê que, "Enquanto algum dos credores solidários não demandarem o devedor comum [...]", apenas esse credor deverá receber o objeto da prestação, tendo sido o único a pleiteá-la. Logo, uma vez iniciada a demanda, opera-se o que se denomina prevenção judicial: o devedor somente se libera pagando ao credor que o acionou; não tendo mais a faculdade de pagar senão a ele, ao contrário do que ocorreria até o momento da instauração da instância, quando era lícito pagar a qualquer um.

Assim, quando um dos credores solidários demandar judicialmente ou extrajudicialmente o devedor, cessará o direito de escolha do devedor, motivo pelo qual apenas esse credor deverá receber o objeto da prestação. De igual modo, não se cogita a possibilidade de outro cocredor da obrigação solidária opor-se ao pagamento em decorrência do fenômeno da prevenção importado do direito processual. Portanto, se não foi este o responsável por acionar o devedor, este último não poderá efetuar o pagamento a ele.

Nesse sentido, há mora accipiendi se o cocredor que acionou o devedor insurgir-se contra o pagamento injustificadamente; nesse caso estaria configurada uma hipótese para a propositura da ação de consignação em pagamento pelo devedor (Gonçalves, 2015, p. 291). Em outras palavras, somente se verifica, nos casos de obrigações solidárias de trato sucessivo, a possibilidade de cabimento de ação de consignação em pagamento com fundamento nos incisos I e II do artigo 335 do CC, quando o credor acionado inicialmente pelo devedor recusa-se, imotivadamente, a receber a prestação.

Portanto, o procedimento da ação de consignação em pagamento existe para atender as peculiaridades do direito material, cabendo às regras processuais regular tão somente o procedimento para o reconhecimento judicial da eficácia liberatória do pagamento especial. Na consignação em pagamento, o depósito tem força de pagamento, e a ação tem por finalidade ver atendido o direito material de o devedor liberar-se da obrigação a que está adstrito. Sendo, assim, "é o meio hábil para que o devedor possa exonerar-se da obrigação, obtendo, com o depósito da coisa devida, os efeitos do pagamento. É necessário para que se alcance tal fim, que a recusa do credor em receber seja injusta".

\subsubsection{A suppressio e a surrectio como manifestações da boa-fé objetiva albergadas pela ação de consignação em pagamento}

O direito processual não deve ser observado, estritamente, nos quadros de realização do direito material, mas a partir da ótica dos valores constitucionais nos quais se encontra inserido para fins de realização da justiça concreta e da pacificação social (Azevedo, 2004, pp. 10-11). Nessa moldura em que deve encontrar-se o direito processual, o princípio da boa-fé impede que o processo fique preso às exigências meramente formais e, consequentemente, dissociado dos valores e dos interesses sociais.

Nessa perspectiva, nota-se a importância da boa-fé enquanto princípio geral do direito em todos os atos jurídicos, no exercício dos direitos e no cumprimento das obrigações. Desse modo, os caminhos do processo são traçados por balizas delimitadas pela lealdade processual e pela boa-fé objetiva, as quais, uma vez observadas, conduzem à efetividade da prestação da tutela jurisdicional.

Assim, de acordo com Díez-Picazo (1986, pp. 19-20), a boa-fé é considerada uma fonte de criação de deveres de conduta especiais exigíveis em cada caso, conforme a natureza da relação jurídica e a finalidade perseguida pelas partes por meio dela. As partes não se devem somente aquilo que elas mesmas estipulam ou o que determina o texto legal, mas tudo o que em cada situação impõe a boa-fé.

Ao observar a importância desse princípio como instrumento de reprodução dos valores fundamentais estabelecidos 
na Carta Magna de 1988, entende-se que a sua concretização dá-se mediante os seus deveres anexos. À luz dessa compreensão, é que se busca, mediante a ação de consignação em pagamento, efetivar a atuação da boa-fé objetiva, visto que aquela é o meio processual adequado para o devedor liberar-se do vínculo obrigacional (Gonçalves, 2019, pp. 13-15), nos casos em que se verifica comportamento diverso do praticado costumeiramente pelo credor.

Dessa forma, a ação de consignação em pagamento viabiliza a satisfação dos interesses da parte que agiu em conformidade com a boa-fé objetiva. Isto é, nos casos em que há a prática de comportamentos que rompem com o princípio da confiança gerado pelo credor no devedor de que os deveres/direitos não seriam exigidos na forma previamente convencionada, a ação consignatória vem a ser um veículo de efetividade do princípio da boa-fé, uma vez que a suppressio e a surrectio constituem fundamento para o devedor alegar mora accipiendi e, assim, propor a ação.

A partir disso, cabe realçar que os institutos da suppressio e da surrectio modificam tacitamente (Tartuce, 2017, p. 142) a relação jurídica em uma obrigação cujos credores encontram-se em mora, alterando inclusive o local de propositura da ação de consignação em pagamento, em caso de pagamento reiteradamente feito em local diverso do consignado em contrato. De fato, o que se almeja é demonstrar que tanto a supressão ou o nascimento de um novo direito concorrem para o surgimento de uma nova circunstância jurídica, a qual, se não observada, frustraria a confiança da contraparte, violando a boa-fé (Cordeiro, 2007, p. 779).

Logo, havendo a real impossibilidade do pagamento voluntário por recusa injusta de receber a prestação por parte do credor (Theodoro Júnior, 2016, p. 50), em decorrência da frustração de uma expectativa esperada pelo credor por conduta praticada anteriormente, é possível a propositura da ação consignatória, tendo como fundamento a configuração da suppressio e da surrectio.

Nesse caso, estariam configurados os dois institutos da boa-fé objetiva, ensejando a possiblidade de o devedor ajuizar ação de consignação em pagamento em decorrência de recusa injustificada para o recebimento da obrigação. Isso significa que há presunção relativa (juris tantum) de que o credor renunciou (suppressio) ao lugar da prestação quando, reiteradamente, o devedor realizou o adimplemento da obrigação em lugar diverso do pactuado, fato que fez surgir, com igual validade, o direito subjetivo do devedor de continuar a fazer o pagamento em local diverso do contratado (surrectio), não podendo o credor a isso se opor, pois houve a perda do direito pelo decurso do tempo, ocorrendo, assim, a modificação tácita do negócio jurídico.

Nessa toada, os institutos mencionados têm reconhecida a sua incidência em situações jurídicas em que o credor se mantém inerte por um longo período, sem cobrar a situação jurídica inicialmente avençada. Com essa inércia do credor, o próprio direito material deixa de existir, em razão de seu comportamento continuado e reiterado, que fez nascer no devedor a expectativa de que não mais seria chamado para o exercício desse direito.

Logo, o reconhecimento dos institutos da boa-fé somente poderá ensejar o ajuizamento da ação de consignação em pagamento em caso de obrigações cujo credor se nega a receber, porque adimplidas em lugar diverso do pactuado, bem como se a prática de tal conduta for suficientemente longa para que haja a limitação do exercício do direito.

Em síntese, a ação de consignação em pagamento é um veículo de efetividade da boa-fé objetiva porque permite a liberação do vínculo obrigacional pelo devedor, pela repetição sistemática, constante e continuada de um determinado comportamento, criando um direito novo. É veículo de efetividade do princípio da boa-fé objetiva quando prevê a suppressio e a surrectio como fundamento para a alegação da mora accipiendi pelo credor, permitindo, assim, que a prática de comportamentos, adotados pelo devedor e mantidos pelo credor, gerando confiança, seja albergada pelo legislador, reiterando que o processo deve ser pautado por valores e interesses sociais, a fim de que possa atingir a efetividade da prestação da tutela jurisdicional. 


\section{Conclusão}

Ao devedor não cabe apenas o dever jurídico de cumprir a prestação pactuada, mas cabe também o direito de fazê-lo. “O dever de manter a palavra - segundo Cogliolo (1915, p. 234) - é uma das mais lentas conquistas da civilização". Fazer cessar os juros e libertar-se de uma obrigação e das responsabilidades pelos riscos, juros ou correção monetária da prestação são alguns fatos suficientes para justificar o direito impostergável do devedor, imprimindo-lhe um padrão de confiança. O devedor, desse modo, não pode estar sujeito ao arbítrio do credor, quer no sentido da eternização do vínculo, quer na subordinação dos seus efeitos à vontade exclusiva daquele.

A boa-fé objetiva nos domínios do direito processual civil estabelece as balizas do agir, permitindo a harmonização das garantias constitucionais processuais, de modo a exigir um comportamento pautado pela lealdade e pela honestidade daqueles que participam da relação processual. A boa-fé objetiva enquanto cláusula geral irradia o seu conteúdo em todos os espectros do processo civil, regendo as relações entre as partes.

Sendo assim, nos casos de constatação da ocorrência de uma oferta real e efetiva por parte do devedor, bem como da recusa injustificada por parte do credor, a boa-fé é o instituto que deverá ser observado, a fim de regular a conduta da parte que age de forma desleal e arbitrária. Nessa perspectiva, ao longo do presente artigo, observou-se que a ação de consignação em pagamento é um modo extintivo da obrigação, já que também interessa ao devedor o cumprimento da obrigação, a fim de liberar-se do vínculo a que se encontra adstrito.

Diante disso, foi possível notar que a configuração da mora do credor - hipótese de cabimento da ação de consignação em pagamento - está intimamente associada aos casos em que o cumprimento da obrigação é realizado, durante um lapso temporal, de forma diversa do pactuado. Assim, permite-se verificar que os institutos da boa-fé figuram como fundamento para o ajuizamento de ação de consignação em pagamento, justamente nos casos em que o credor, inicialmente, mantém-se inerte, modificando tacitamente a relação jurídica e, posteriormente, quer que o devedor realize o pagamento das parcelas restantes conforme o avençado.

O certo é que, sob o enfoque da boa-fé objetiva, da solidariedade, da responsabilidade e da confiança, altera-se a essência da relação jurídica, exigindo-se das partes uma postura mais ética, especialmente no que tange ao limite dos seus direitos subjetivos. Em razão do exposto, conclui-se que a ação de consignação em pagamento tem-se mostrado um importante mecanismo para ver atendido o direito material do devedor de liberar-se da obrigação mediante provimento jurisdicional, nos casos em que a obtenção da quitação é obstada pela prática de comportamento que frustra a expectativa do credor.

O tema continuará sendo objeto da atenção das autoras, em publicações futuras, quando serão analisados os desdobramentos da ação de consignação em pagamento, como mecanismo técnico-jurídico necessário e suficiente para assegurar uma efetiva participação do executado na dialética do processo, de forma a caracterizá-la como direito de defesa apto a afastar a execução e seu ônus.

\section{Referências}

Alonso, J. O. (2019). A boa-fé objetiva e a aplicação dos institutos da supressio e da surrectio nos contratos brasileiros pós-modernos. Revista dos Tribunais, $102,19-42$.

Arenal, L., Carvalho, N. G. de M. (2015). Ação de consignação em pagamento. Revista Síntese: Direito Imobiliário, 6 (29), $30-44$.

Azevedo, A. V. (2004). Teoria geral das obrigações. Atlas.

Baumgärtel, G. (1973). Treu und Glauben im Zivilprozess. Zeitschrift für Zivilprozess, 3(86), 353-372.

Biscardi, A. (1951). Secundum nostrae civitatis iura. Studi Senesi, 38, 40-49.

Brasil (1988). Constituição da República Federativa do Brasil. Senado Federal.

Bueno, C. S. (2016). Manual de direito processual civil (2a ed.). Saraiva. 
Cambi, E., Dotti, R., Pinheiro, P. E. d'A., Martins, S. G., \& Kozikoski, S. M. (2017). Curso de processo civil completo. Revista dos Tribunais.

Coelho, F. U. (2020). Curso de direito civil (8a ed.). Revista dos Tribunais.

Cogliolo, P. (1915). Filosofia do direito privado. Liv. Classica de A. M. Teixeira.

Cordeiro, A. M. da R. e M. (2007). Da boa fé no direito civil. Almedina.

Didier Jr., F., Braga, P. S., \& Oliveira, R. A. de (2020). Curso de direito processual civil (20a ed.). JusPodivm.

Díez-Picazo, L. (1986). Prólogo. In F. Wieacker. El principio general de la buena fe (2a ed.), pp. 9-23), Civitas.

Diniz, M. H. (2007). Curso de direito civil brasileiro: teoria das obrigações (22a ed.). Saraiva.

Donizetti, E. (2017). Novo Código de Processo Civil comentado. Atlas.

Falco, G. (2010). La buona fede e l'abuso del diritto: principi, fattispecie e casistica. Giuffrè.

Faro, J. P. (2012). Consignação de pagamento em execução: uma hipótese incomum e possível. Revista de Processo, 37 (214), 401-411.

Gagliano, P. S., \& Pamplona Filho, R. (2018). Novo curso de direito civil: obrigações (19a ed.). Saraiva.

Gajardoni, F. da F., Dellore, L., Roque, A. V., \& Oliveira Jr., Z. D. de (2018). Processo de conhecimento e cumprimento de Sentença: comentários ao CPC de 2015 (2a ed.). Método.

Gama, G. C. N. da. (2008). Direito civil: obrigações. Atlas.

Gil, A. C. (2008). Métodos e técnicas de pesquisa social (6a ed.). Atlas.

Gonçalves, C. R. (2015). Direito civil brasileiro: teoria geral das obrigações (12a ed.). Saraiva.

Gonçalves, M. V. R. (2019). Processo civil: procedimentos especiais (16a ed.). Saraiva.

Grinover, A. P. (2002). Ética, abuso do processo e resistência às ordens judiciárias: o Contempt of Court. Revista de Processo, 26(102), $219-227$.

Hontebeyrie, A. (2004). Le fondement de l'obligation solidaire en droit privé français. Economica.

Lima, D. S. B. (2011). Origens do pagamento por consignação nas obrigações em dinheiro. Doutrinas Essenciais Obrigações e Contratos, 2, $773-824$.

Marcato, A. C. (1996). Ação de consignação em pagamento (5a ed.). Malheiros.

Marconi, M. de A., \& Lakatos, E. M. (2003). Fundamentos de metodologia científica (5a ed.). Atlas.

Marinoni, L. G., Arenhart, S. C., \& Mitidiero, D. (2016). Curso de processo civil (3a ed.). Revista dos Tribunais.

Martins, S. G. (2005). A defesa do executado por meio de ações autônomas: defesa heterotópica (2a ed.):: Revista dos Tribunais.

Martins-Costa, J. (2018). A boa-fé no direito privado: critérios para a sua aplicação (2a ed.). Saraiva.

Mello, C. de M. (2017). Direito civil: contratos (2a ed.). Freitas Bastos Editora.

Morais, E. (2019). A boa-fé objetiva pré-contratual: deveres anexos de conduta. Revista dos Tribunais.

Nery, R. M. de A., \& Nery Junior, N. (2014). Manual de direito civil: obrigações. Revista dos Tribunais.

Neves, J. G. A. (2016). A Suppressio (Verwirkung) no direito civil. Almedina.

Noronha, F. (2013). Direito das obrigações (4a ed.). Saraiva.

Patti, S. (1999). Verwirkung. In Digesto delle Discipline Privatistiche, t. XIX (4a ed.), pp. 722-730. Unione Tipografico-Editrice Torinese.

Pereira, C. M. da S. (2017). Instituições de direito civil: teoria geral das obrigações (29a ed.). Forense.

Prodanov, C. C., \& Freitas, E. C. de (2013). Metodologia do trabalho científico: métodos e técnicas da pesquisa e do trabalho acadêmico. (2a ed.). Porto Alegre: Universidade FEEVALE.

Reale, M. (2010). A boa-fé no Código Civil: doutrinas essenciais de direito civil (v. 2). Revista dos Tribunais.

Romain, J.-F. (2000). Théorie critique du príncipe général de bonne foi en droit privé: des atteintes à la bonne foi, en général, et de la fraude, en particulier ("Fraus omnia corrumpit"). Bruylant.

Salvatore, M. (1950). Le basi romanistiche del Codice Civile. Unione Tipografico-Editrice Torinese.

Savigny, F. K. von (1898). Sistema del diritto romano attuale (V. Scialoja, Trad.). Unione Tipografico-Editrice Torinese .

Silva, C. V. do C. e (2006). A obrigação como processo. FGV. 
Research, Society and Development, v. 10, n. 5, e28110514787, 2021

(CC BY 4.0) | ISSN 2525-3409 | DOI: http://dx.doi.org/10.33448/rsd-v10i5.14787

Silva, C. V. do C. e (1977). Comentários ao Código de Processo Civil: v. 11. Revista dos Tribunais.

Taborda, M. G. (2001). A jurisprudência clássica romana e a construção de um direito negocial fundado na fides. Estudos Jurídicos, 34, 5-36.

Tartuce, F. (2017). Direito civil: teoria geral dos contratos e contratos em espécie (12a ed.). Forense.

Theodoro Júnior, H. (2016). Curso de direito processual civil: procedimentos especiais (50a ed.). Forense.

Venosa, S. de S. (2005). Direito civil: teoria geral das obrigações e teoria geral dos contratos (5a ed.). Atlas.

Zanetti, C. de S. (2008). Direito contratual contemporâneo: a liberdade contratual e sua fragmentação. Forense. 